\title{
Has COVID-19 Changed the Future of Physiotherapy?
}

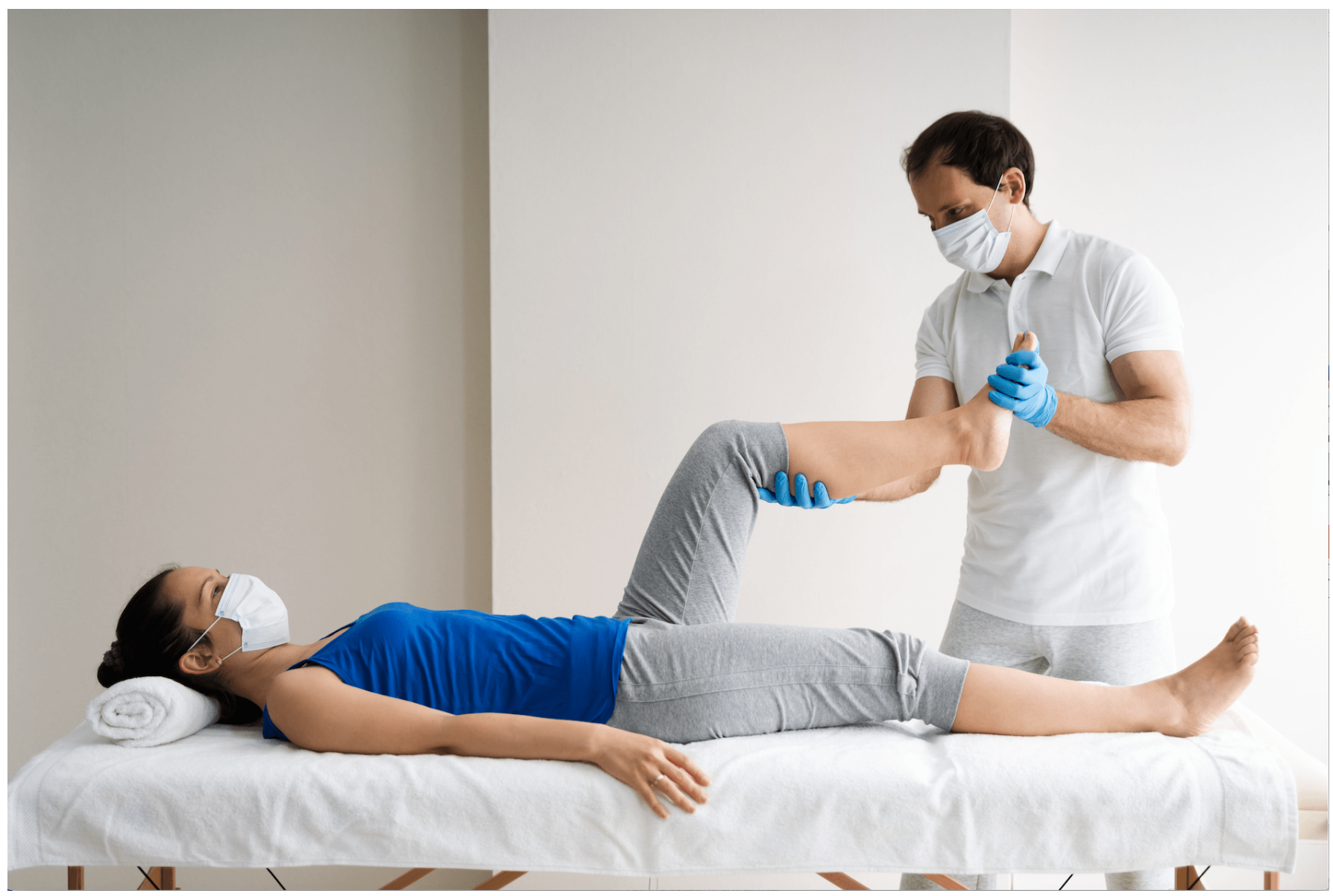

Qais Gasibat, Tengku Fadilah Tengku Kamalden

University Putra Malaysia (UPM), Kuala Lumpur, Malaysia, 43000 Serdang, Selangor, Malaysia

Life post Coronavirus disease (COVID-19) will not be same for anyone and like so many professions it will be a challenging time for physiotherapists and health care providers. A lot of practitioners are going through economic challenges because of the imposed lock down in various countries. As the situation recovers and more people resume their working life, we physiotherapists should be more concerned now while attending to our clients. As front-line practitioners, physiotherapists are more prone to have direct contact with patients affected with COVID-19.

Minghelli et al. [1] recorded that 453 (73.2\%) of physiotherapists have changed their normal work 
schedules as a result of the pandemic, while 166 (26.8\%) work as usual but take precautionary measures such as regular hand washing (21.5\%), using masks (20.3\%), practising material disinfection (19.3\%), and using gloves (19.3\%). As with other physiotherapists who do not work in person ( $n=453), 267$ (58.9\%) do remote monitoring of their patients, while 186 (41.1\%) do not track their patients. The most common methods physiotherapists add to distance monitoring of their patients include: written care orders (38\%), use of instructional videos (26.7\%), and real-time video conferencing (23.5\%). It is no wonder that most physiotherapists are avoiding face-to-face therapy due to COVID-19.

Despite physiotherapy being an important service, hands-on-therapy is only given in crucial cases to avoid being infected with COVID-19, which is ultimately forcing practitioners to close their doors. Not everyone has the required tools and equipment in their houses compared to what they can get in a care centre.

Some of the practices that can be adopted include disposable personal protective equipment, which requires to be changed in between patients, attending patients as per appointments but with thorough screening, facilitation of social distancing by reducing the number of therapists and patients in the same place at the same time, and moving towards digital physiotherapy for guiding and assessing patients while performing exercises. These practices will enhance the reduction of the risk of transmission of infection. Digital physiotherapy and tele-rehabilitation practice are becoming more recognized along with gaining greater acceptance and recognition from insurance companies and regulatory bodies with the restriction of movement. Virtual care can act as a decent choice for clients who feel unwell, since it can assure that patients still obtain treatment without affecting other patients.[2] Physiotherapists currently in primary care can utilise tele-health and tele-physiotherapy under limited conditions during the pandemic though it has been previously applied in the public system of the healthcare sector. COVID-19 has resulted in tele-physiotherapy consultations as a free service in Australia.[3]

During the operation of the movement control order in Malaysia, the physiotherapists worked day and night to generate 2 to 3 video content pieces per day for educating the people in our community about the process of continuing to provide them help in reaching their goals through tele-health. Most patients could not think of getting consultations via physiotherapy as the scope of manual therapy was not possible via telehealth, such as mobilisations and massage that most people assume could reach their rehabilitation goals.

It is further assumed that physiotherapy will never return to its previous manner where clinics would be able to completely follow old practices. Physiotherapists and physiotherapy clinics will need to go ahead and adapt to the continuously changing world that has arisen from the current crisis. This will be a onetime opportunity for the physiotherapy profession to grow and move forward.

\section{Key Points}

1. Life after COVID-19 pandemic is not going to be the same. This is a challenging time for many physiotherapists and other health care providers.

2. Most physiotherapists have adapted to monitor their patients from a distance using digital tools that are new to their professional activity. 


\section{Corresponding author}

Qais Gasibat, Pt BSc MSc

Orthopaedic and Sports Physiotherapist

University Putra Malaysia (UPM)

43000 Serdang, Selangor, Malaysia

Orcid: https://orcid.org/0000-0002-1193-965X

Email: drqaiss9@gmail.com

Phone 00601121348089

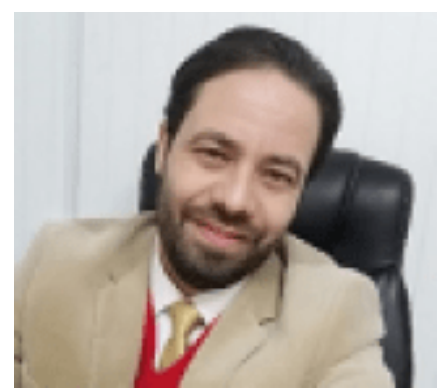

\section{References}

1. Minghelli B, Soares A, Guerreiro A, Ribeiro A, Cabrita C, Vitoria C, Nunes C, Martins C, Gomes D, Goulart F, Santos RM. Physiotherapy services in the face of a pandemic. Revista da Associação Médica Brasileira. 2020 Apr;66(4):491-7.

2. Bettger JP, Thoumi A, Marquevich V, De Groote W, Battistella LR, Imamura M, Ramos VD, Wang N, Dreinhoefer KE, Mangar A, Ghandi DB. COVID-19: maintaining essential rehabilitation services across the care continuum. BMJ Global Health. 2020 May 1;5(5):e002670.

3. Stanhope J, Weinstein P. Learning from COVID-19 to improve access to physiotherapy. Australian Journal of Primary Health. 2020 Aug 21;26(4):271-2. 